\title{
Polydopamine Coating on Titanium Affects Osteoblastic Differentiation to a Greater Degree than Does Surface Roughness
}

\author{
Seyed Mohsen Latifi, Ravi Shankar, Henry J. Donahue* \\ Bone Engineering Science and Technology (BEST) Lab, Virginia Commonwealth University, Richmond, USA \\ Email: *hjdonahue@vcu.edu
}

How to cite this paper: Latifi, S.M., Shankar, R. and Donahue, H.J. (2020) Polydopamine Coating on Titanium Affects Osteoblastic Differentiation to a Greater Degree than Does Surface Roughness. Advances in Materials Physics and Chemistry, 10, 339-349.

https://doi.org/10.4236/ampc.2020.1012027

Received: November 19, 2020

Accepted: December 28, 2020

Published: December 31, 2020

Copyright () 2020 by author(s) and Scientific Research Publishing Inc. This work is licensed under the Creative Commons Attribution International License (CC BY 4.0).

http://creativecommons.org/licenses/by/4.0/ (c) (i) Open Access

\begin{abstract}
Biointerface design can greatly influence cell behavior. Therefore, in this study we examined the effects of three surface characteristics, roughness, chemistry, and wettability, on osteoblastic cell differentiation. We examined osteoblastic differentiation on titanium (Ti) samples with four levels of roughness (average roughness: $148.6 \pm 23.1,42 \pm 6.2,14.3 \pm 5.5,7.2 \pm 1.6 \mathrm{~nm}$ ) with or without a nanolayer coating of polydopamine (PDA). In vitro osteogenic differentiation was evaluated by quantifying alkaline phosphatase (AP) activity of human fetal preosteoblastic (hFOB 1.19) cells. The change in surface chemistry of Ti samples as a result of PDA coating was assessed by XPS analysis and water contact angle measurement. Results demonstrated that PDA treated samples were more hydrophilic, compared to untreated samples, and this was substrate roughness independent. Moreover, with the exception of the substrate with an oriented texture of surface nanotopography (RTi-4), the presence of a PDA nanolayer increased AP activity independent of substrate roughness. Our results suggest that surface chemistry and wettability, induced by a PDA nanolayer coating, had a greater effect on osteoblastic differentiation than did surface roughness.
\end{abstract}

\section{Keywords}

Surface Chemistry, Roughness, Polydopamine, Wettability,

Osteoblastic Differentiation

\section{Introduction}

The interaction between bone biosubstitutes and cells is an important consideration when developing novel bone regeneration strategies because this interaction plays a key role in the success or failure of the bone biosubstitutes. This empha- 
sizes the importance of examining the effect of biointerface properties on cellular behavior [1]. Among biointerface properties, surface roughness, wettability, and chemistry are three crucial parameters [2]. For example, titanium is widely used as a bone biosubstitute for dental and orthopedic application due to its favorable mechanical properties and biocompatibility [3] [4] [5]. Furthermore, manipulation of titanium's biointerface properties including roughness, wettability [5] and surface chemistry [5] [6] has the potential to regulate cell behavior.

Surface roughness, ranging from micro to nanoscale, of a bone biosubstitute is an important biointerface property and plays an important role in osseointegration, biomechanical fixation, and cell behavior [1]. As regards cell behavior, surface roughness can affect cell behavior [7]. For instance, titanium surfaces with micron size roughness $(<10 \mu \mathrm{m})$ have the potential to increase osteoblastic cell adhesion, proliferation, differentiation and mineralization [8] [9]. Within a mean roughness $(\mathrm{Ra})$ range of $1-6 \mu \mathrm{m}$, rougher surfaces $(\mathrm{Ra}=5.70 \mu \mathrm{m})$ have a greater effect on osteoblastic proliferation than smoother surfaces $(\mathrm{Ra}=1.12$ $\mu \mathrm{m})$ [7]. Khang et al. [10] examined the effect of flat, nanometer, and sub-micron surface features of titanium with root mean square roughness (Rq) within the range of $0-12 \mathrm{~nm}$ on osteoblast cells adhesion. They found that osteoblasts display stronger adhesion to sub-micron and nanometer surface scales of titanium compared to flat surfaces.

In addition to surface roughness, surface wettability (or surface energy) is another important biomaterial characteristic that can influence cell adhesion and activity [11]. The wettability of a surface can be defined by measuring the water droplet contact angle. A contact angle less than 90 degrees and more than 90 degrees are representative of a hydrophilic and a hydrophobic surface, respectively [12]. Osteoblastic cells display greater adhesion, and consequently greater viability, on hydrophilic surfaces than on hydrophobic surfaces [13].

A biocompatible [14] nanolayer of polydopamine (PDA), which can be applied as a coating to any material, has the potential to change the surface chemistry of the material [15] [16]. PDA nanolayers can induce surface bioactivity [14] [16] which would lead to a strong chemical bonding between bone biosubstitutes and bone tissue [17]. They can also serve to create multifunctional surfaces on the bone biosubstitute to promote bone regeneration via immobilization of active biomolecules such as bone morphogenic protein (BMP-2) [18]. The advantages of PDA nanolayers for surface modification of bone biosubstitutes are highlighted in a review article by Huang et al. [19].

Based on the importance of biointerface properties including roughness, surface chemistry, and wettability on regulation of cell behavior, the aim of this study was to evaluate which factor (surface roughness, chemistry, or wettability) has a greater effect on osteoblastic cell differentiation.

\section{Experimental Procedures}

\subsection{Titanium Preparation}

To create different degrees of roughness on the surface of titanium (uncoated 
rough $\mathrm{Ti}$ samples), titanium samples were machined from $99.7 \%$ commercially pure Ti (Sigma-Aldrich) into $10 \mathrm{~mm} \times 10 \mathrm{~mm} \times 2 \mathrm{~mm}$ squares. They were then cast in epoxy (Buehler) and sequentially polished to four degrees of roughness on a Buehler Ecomet 300 grinder-polisher. The first level was polished with 220 grit silicon carbide grinding paper $(58 \mu \mathrm{m}$ avg. $\mathrm{d}$, Buehler) until plane. The second level was polished with 220 grit then 600 grit (15 $\mu \mathrm{m}$ avg. d, Buehler). The next two levels were further polished with nanocrystalline diamond suspension ( $3 \mu \mathrm{m}$ avg. $d$, Buehler) and colloidal silica $(0.06 \mu \mathrm{m}$ avg. $d$, Buehler). After polishing, the samples were cut out of the epoxy and ultrasonically degreased in acetone twice for 10 minutes each time. They were then washed for 10 minutes in isopropyl alcohol and finally deionized water. The labels for the uncoated rough Ti samples (RTi-1 to 4) are shown in Table 1.

To create samples with different surface chemistries (surface modified Ti), Ti substrates with different degrees of roughness (uncoated rough Ti samples) were coated with a self-assembled PDA nanolayer. Ti substrates were incubated for 24 hours at $37^{\circ} \mathrm{C}$ in a $2 \mathrm{mg} \cdot \mathrm{mL}^{-1}$ dopamine-hydrochloride solution in $10 \mathrm{mM}$ tris buffer, $\mathrm{pH}$ adjusted to 8.5 according to Lee et al. [15]. The coated samples were thoroughly rinsed with deionized water and air dried for $24 \mathrm{~h}$. These samples were labeled CTi-1 to 4 (Table 1).

\subsection{Characterization of Surface Roughness, Chemistry and Wettability}

Atomic force microscopy (AFM, Bruker FastScan), in the tapping mode at a scanning frequency of $0.5 \mathrm{~Hz}$, was used to examine the topography and surface roughness of Ti substrates after mechanical polishing. X-ray photoelectron spectroscopy (XPS, PHI Versa Probe III), using a monochromatic Al Ka X-ray source $(1486.6 \mathrm{eV})$ under the working pressure of $10^{-7} \mathrm{~Pa}$, was used to examine the surface chemistry of PDA treated and untreated Ti samples. Survey scan spectra were measured at pass energy of $280 \mathrm{eV}$. Static water contact angle of the samples was also quantified with a Ramé-Hart goniometer, using $5 \mu$ l of distilled water.

Table 1. The labels used to identify investigated samples.

\begin{tabular}{lc}
\hline Labels & Description of Ti sample's preparation \\
\hline RTi-1 & 220 grit silicon carbide \\
RTi-2 & 220 and 600 grit silicon carbide \\
RTi-3 & 220 and 600 grit silicon carbide and $3 \mu \mathrm{m}$ diamond solution \\
RTi-4 & 220 and 600 grit silicon carbide, $3 \mu \mathrm{m}$ diamond solution, and $0.06 \mu$ m colloidal silica \\
CRTi-1 & Same as RTi- 1 and PDA coated \\
CRTi-2 & Same as RTi-2 and PDA coated \\
CRTi-3 & Same as RTi-3 and PDA coated \\
CRTi-4 & Same as RTi- 4 and PDA coated \\
\hline
\end{tabular}




\subsection{Examination of Osteoblastic Differentiation}

Material samples for in vitro studies were sterilized by exposing the samples to 2 hours of UV radiation. To evaluate in vitro osteoblastic differentiation, human fetal pre-osteoblastic hFOB 1.19 cells were seeded on samples at a density of $76 \times$ $10^{3}$ cells/well and cultured in DMEM/F12 with 10\% FBS, $1 \%$ Antibiotic-Antimyotic, $10^{-8} \mathrm{M}$ menadione, $100 \mu \mathrm{g} \cdot \mathrm{mL}^{-1}$ ascorbic acid, and $10^{-8} \mathrm{M} \mathrm{1,25-dihydroxy} \mathrm{vita-}$ min D3 for $7 \mathrm{~d}$ in $5 \% \mathrm{CO}_{2}$ at $39.5^{\circ} \mathrm{C}$, with media replaced every 2 days. Alkaline phosphatase (AP) activity, an indicator of osteoblastic differentiation, was quantified by assessing the conversion of p-nitrophenyl phosphate to p-nitrophenol [20]. Absorption was measured with a microplate reader (iMarkTM Microplate Reader, Bio-rad USA) at $415 \mathrm{~nm}$, and the specific enzyme activity was estimated from a p-nitrophenol standard curve after normalization to total protein content (PierceTM BCA Protein assay Kit).

\subsection{Statistical Analysis}

All quantitative data in this study are presented as mean \pm standard deviation. Significant differences in data were analyzed by ANOVA, followed by Tukey's post hoc test or Student-Newman-Keuls Method. The differences were considered significant if $\mathrm{p}<0.05$.

\section{Results and Discussion}

\subsection{AFM Analysis}

To examine the effect of mechanical polishing we used AFM in the height mode (Figure 1). Different mechanical polishing processes led to Ti surfaces with different topographies. Average roughness $(\mathrm{Ra})$ and root mean square roughness (Rq) of the Ti samples that were exposed to different types of mechanical polishing are shown in Figure 2. The Ra for RTi-1, RTi-2, RTi-3, and RTi-4 substrates was $148.6 \pm 23.1,42 \pm 6.2,14.3 \pm 5.5,7.2 \pm 1.6$ nanometers, respectively. The Rq for RTi-1, RTi-2, RTi-3, and RTi-4 substrates was $188.2 \pm 32.2,51.14 \pm$ $9.5,24.3 \pm 13.2$, and $12.5 \pm 3.3$ nanometers, respectively.

The height profile along the white line marked for each AFM image is shown in Figure 3. There is a trend of reduced height, from micro to nanoscale, of the peak to valley topography from RTi- 1 to RTi- 4 surfaces. Although there was no significant difference between Ra of RTi- 3 and RTi- 4 and Rq of RTi- 3 and RTi- 4 (Figure 2), the height profile for these two samples (Figure 3(c) and Figure $3(d))$ demonstrated that surface topography on RTi-4 is more uniform. Moreover, surface nanotopography on RTi- 4 associates with an oriented texture.

\subsection{XPS Analysis}

PDA coating, as a result of the oxidation of dopamine [15], can result in differing thicknesses, ranging from 10 to $100 \mathrm{~nm}$, on substrates depending on the material interface and incubation time [21]. XPS can determine the chemical composition of a surface with a penetration depth of less than $10 \mathrm{~nm}$ [22]. Due to 


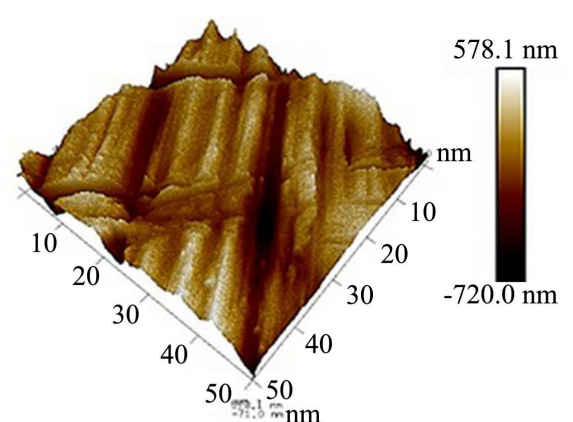

(a)

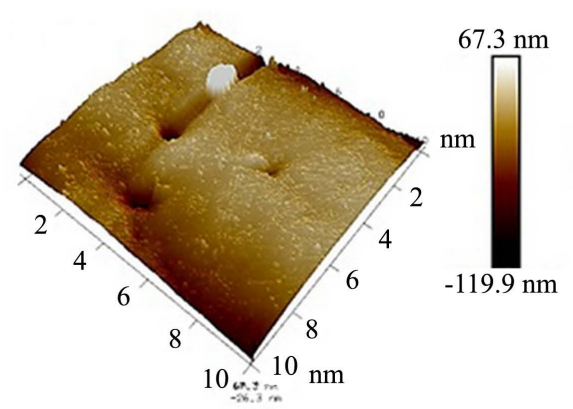

(c)

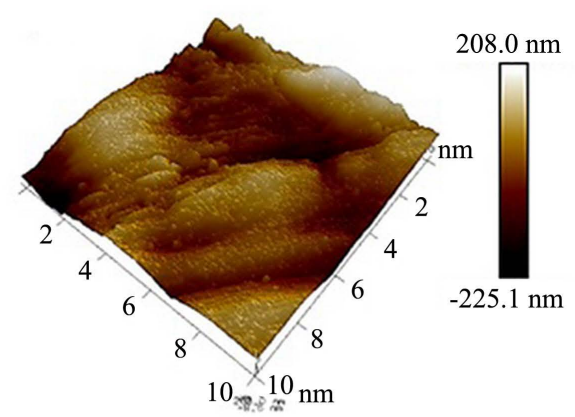

(b)

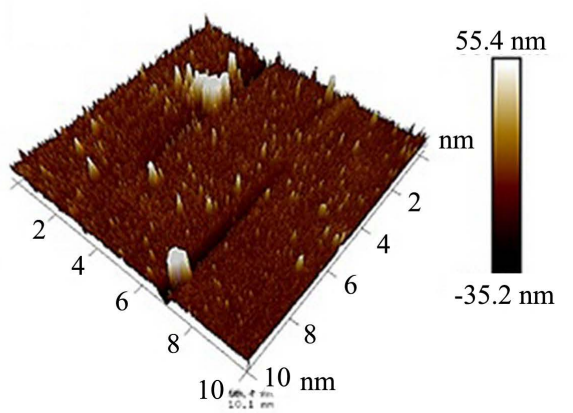

(d)

Figure 1. AFM images of uncoated Ti surfaces with four degrees of roughness; (a) RTi-1; (b) RTi-2; (c) RTi-3; (d) RTi-4.

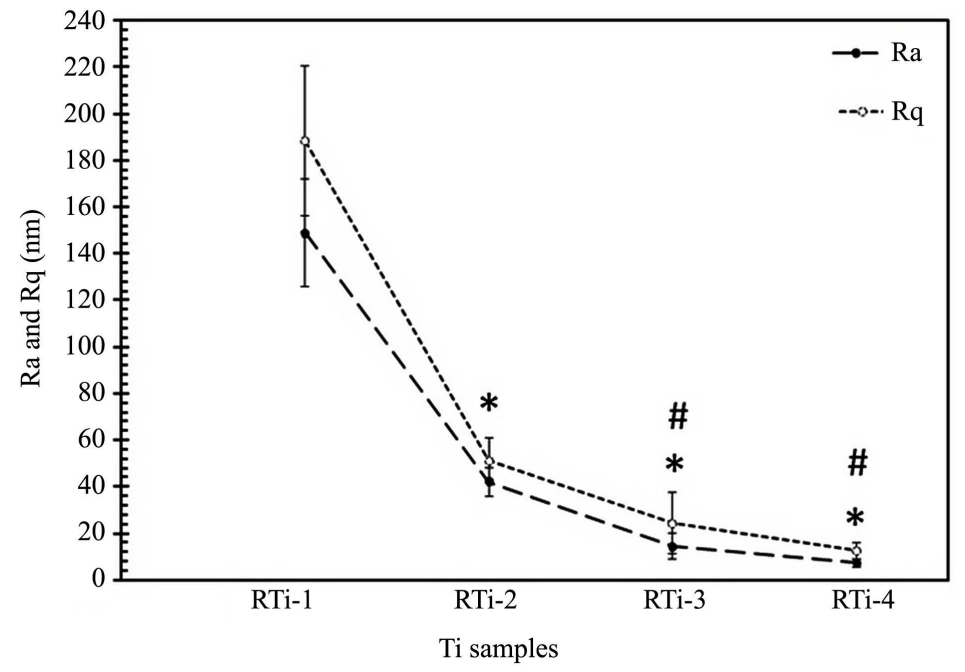

Figure 2. Uncoated Ti samples displayed a gradual decrease in average roughness (Ra) and root mean square roughness $(\mathrm{Rq})$ as a result of mechanical polishing. $\mathrm{n}=5$; ${ }^{\star} \mathrm{p}<0.05$ compared to RTi-1; \# p 0.05 compared to RTi-2.

nanometric features of the PDA layer, XPS analysis was done to demonstrate successful formation of a PDA nanolayer on the surface of the Ti substrates. Figure 4 shows XPS spectra from the surface of RTi- 1 and CRTi- 1 samples as representative of an uncoated $\mathrm{Ti}$ and a coated $\mathrm{Ti}$ with PDA nanolayer, respectively. Three elements including $\mathrm{Ti}, \mathrm{O}$, and $\mathrm{C}$ were detected on the surface of 


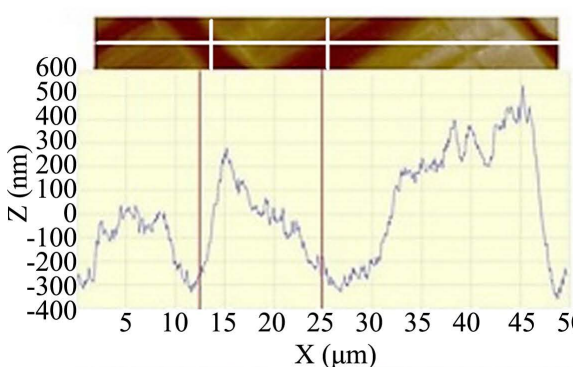

(a)

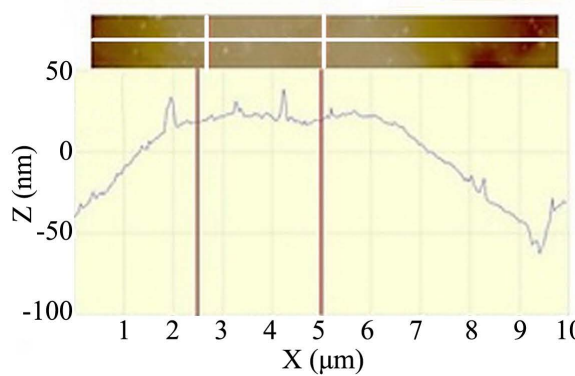

(c)

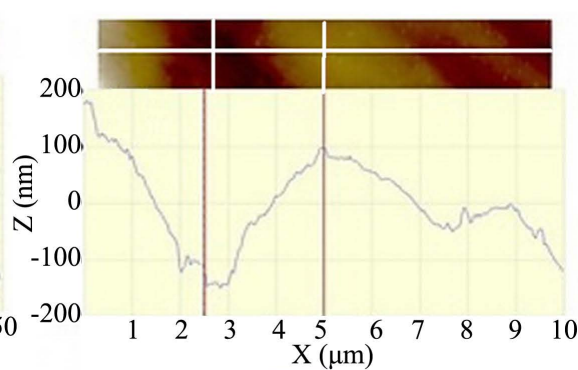

(b)

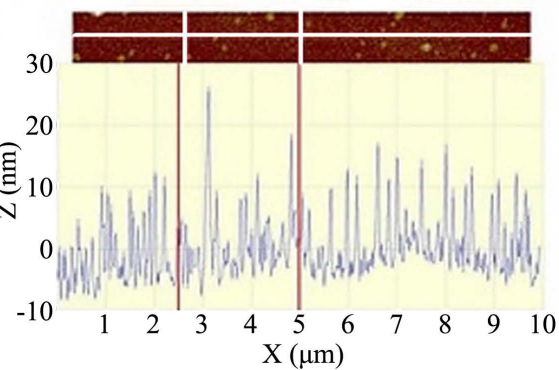

(d)

Figure 3. Height profile along the white line marked in each AFM image; (a) RTi-1; (b) RTi-2; (c) RTi-3; (d) RTi-4.

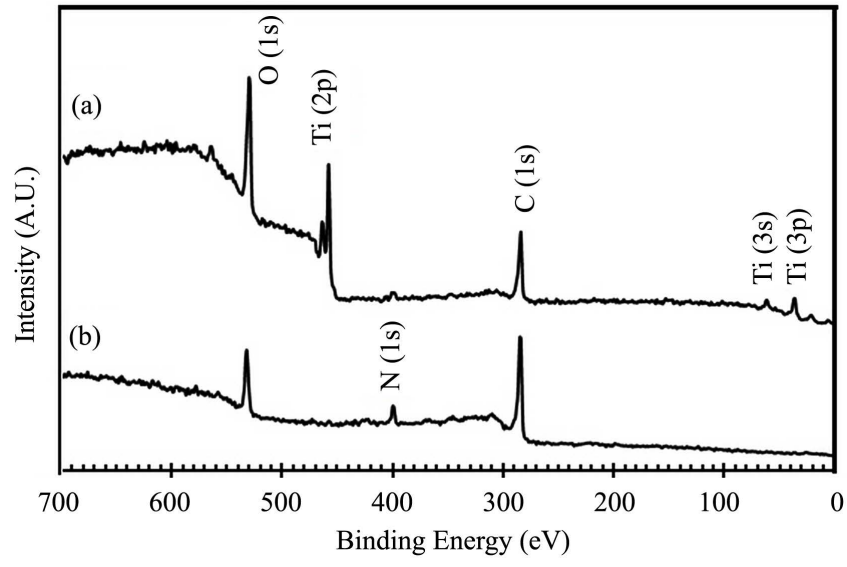

Figure 4. XPS spectra from the surface of (a) RTi-1 (uncoated Ti) and (b) CRTi-1 (coated Ti with PDA monolayer).

RTi-1 (Figure 4(a)). The presence of titanium and oxygen on the surface of RTi-1 is related to a native oxide layer $\left(\mathrm{TiO}_{2}\right)$ which naturally covers titanium surfaces [16]. Exposure of titanium to air or water leads to an instantaneous formation of a titanium oxide layer $(4-6 \mathrm{~nm})$ on its surface [23]. The presence of carbon on the surface results from environmental contamination, as has been reported in several studies [16] [24]. No signals related to Ti were detected in the XPS spectrum of CRTi-1 (Figure 4(b)), but three peaks including C, O, and N were detected on the surface and these presumably originated from the chemical composition of the PDA nanolayer. This suggests that the PDA nanolayer masks the signals from substrate (Ti) and presents a surface with different surface chemistry from the substrate. 


\subsection{Wettability}

The With the exception of sample RTi-4, surface roughness did not significantly affect contact angle of uncoated Ti samples. These results are in agreement with the results reported by Yan et al. [23] that showed no obvious relationship between water contact angle and average roughness $(\mathrm{Ra})$ of Ti-6Al-4V alloy samples in the range of $280 \mathrm{~nm}$ and $9.5 \mathrm{~nm}$. The RTi-4 sample compared to other uncoated Ti samples (RTi-1 to 3 ) had a significantly lower water contact angle, which indicates that the RTi-4 sample is more hydrophilic and consequently has higher surface energy [10] compared to other uncoated Ti samples. This may be attributed to the texture of surface nanotopography as nanotopographic surfaces with more oriented texture display higher surface energies [25].

All Ti surfaces coated with PDA had lower contact angles $\left(\sim 52^{\circ}\right)$ than uncoated Ti surfaces $\left(\sim 73^{\circ}\right)$ (Figure 5), indicating that PDA treatment increased surface hydrophilicity. This can be attributed to the exposed hydrophilic groups, including hydroxyl $(-\mathrm{OH})$ and amino $\left(-\mathrm{NH}_{2}\right)$ groups on the surface of the PDA nanolayer [14]. Moreover, All PDA coated Ti samples had the same surface hydrophilicity as revealed by their similar contact angles. This indicates that the surface hydrophilicity of PDA coated Ti samples was independent from roughness of Ti substrates.

Increasing wettability and consequently surface energy not only improves the interaction of blood with surfaces, but also promotes the spreading and binding of fibrin and matrix proteins. This would positively affect cell attachment and tissue healing [25]. It has been reported that adjusting initial protein interactions is a critical factor in increasing osteoblast-like cell adhesion on the hydrophilic surfaces [13].

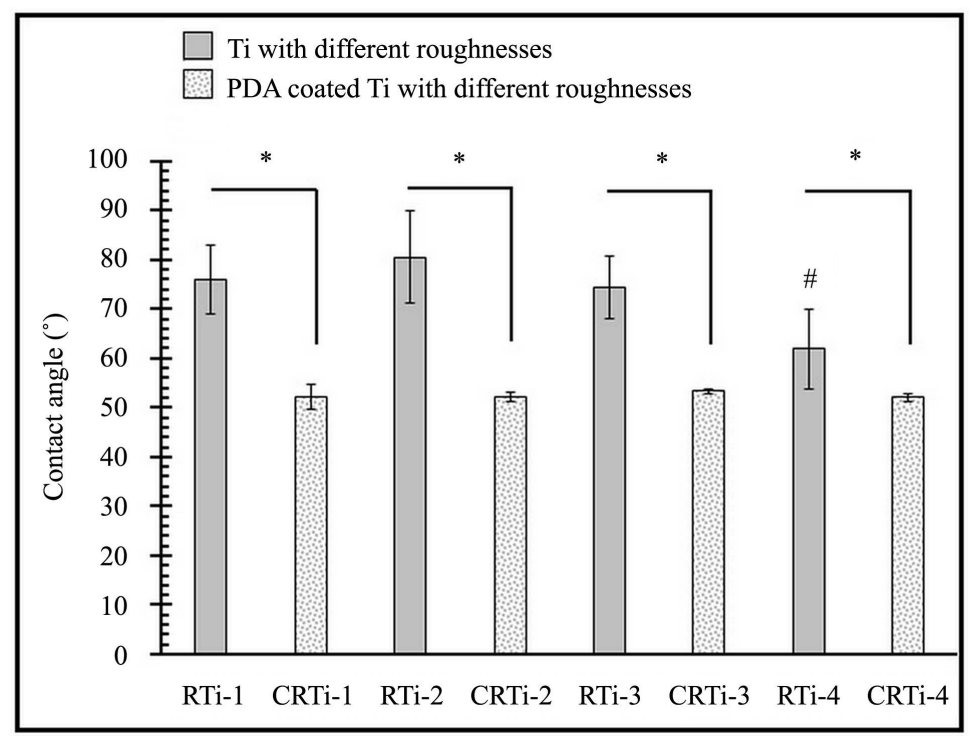

Figure 5. Water contact angle measurements for uncoated and PDA coated Ti samples. $\mathrm{n}$ $=6 ;{ }^{*}$ indicates significant difference, $\mathrm{p}<0.05$ between surfaces with and without PDA within the same roughness group; \# indicates significantly different, $\mathrm{p}<0.05$ from all other roughness groups (RTi-1, RTi-2, RTi-3). 
In the case of hFOB cells, the key role of surface wettability on hFOB cell adhesion was highlighted by Lim et al. [26] [27] as they showed that hydrophilic surfaces $\left(\theta<65^{\circ}\right)$ result in greater cell attachment than do less hydrophilic surfaces with $\theta>65^{\circ}$. This emphasizes the importance of a PDA coating nanolayer on Ti surfaces. We found that all Ti surfaces coated with PDA showed lower contact angles $\left(\sim 52^{\circ}\right)$ than uncoated Ti surfaces $\left(\sim 73^{\circ}\right)$ (Figure 5$)$. Therefore, changing the surface chemistry of Ti surfaces with PDA coating nanolayers led to a change in wettability of Ti surfaces which is favorable for hFOB cell adhesion.

\subsection{Alkaline Phosphatase (AP) Activity}

Differentiation of osteoblasts was evaluated by quantifying AP activity [16] [28]. We found that surface roughness did not affect hFOB AP activity in cells on Ti that had or had not been coated with PDA (Figure 6). However, with the exception of group 4 (sample RTi- 4 and CRTi-4), AP activity was greater in cells cultured on PDA coated samples compared to uncoated samples for all roughness groups.

Previous studies demonstrated that osteoblastic cells (MC3T3-E1 cells) on PDA coated anodized Ti displayed a greater level of cell spreading and cell adhesion compared to cells on uncoated anodized $\mathrm{Ti}$ [16]. They also displayed greater expression of vinculin [16]. Thus the increase wettability in our PDA samples may lead to increased osteoblastic differentiation by increasing cell adhesion and spreading. Indeed, increased cell spreading leads to increased contractility which may enhance osteogenic differentiation [29].

Although the CRTi-4 sample was more hydrophilic than the RTi-4 sample (Figure 5), cells on both surfaces displayed similar AP activity (Figure 6). This may be related to the oriented texture of surface nanotopography of RTi-4 sample. Future studies will examine this possibility.

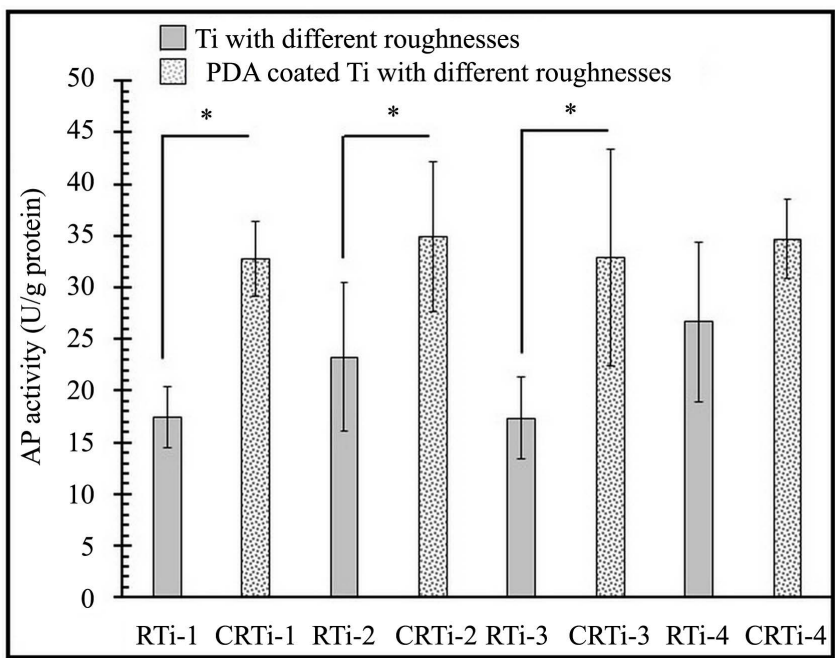

Figure 6. Normalized AP activity of hFOB cells on uncoated and PDA coated Ti samples after $7 \mathrm{~d}$ culturing at $39.5^{\circ} \mathrm{C}$. ( $\mathrm{n}=3$; $^{\star} \mathrm{p}<0.05$ vs uncoated Ti samples). 


\section{Conclusion}

Our results demonstrate that manipulation of surface chemistry (and surface wettability) by coating with a PDA nanolayer plays a more important role in promoting osteoblastic differentiation than does manipulation of surface roughness of the substrate (Ti). Thus, manipulation of surface chemistry by PDA coating may be a simple, economical, and more effective technique to enhance the ability of complex geometries, including novel scaffolds, to promote osteoblastic differentiation and osteogenesis.

\section{Acknowledgements}

This work was supported by the Virginia Commonwealth University College of Engineering Foundation.

\section{Conflicts of Interest}

The authors declare no conflicts of interest regarding the publication of this paper.

\section{References}

[1] Bauer, S., Schmuki, P., von der Mark, K. and Park, J. (2013) Engineering Biocompatible Implant Surfaces: Part I: Materials and Surfaces. Progress in Materials Science, 58, 261-326. https://doi.org/10.1016/j.pmatsci.2012.09.001

[2] Liu, X., Lim, J.Y., Donahue, H.J., Dhurjati, R., Mastro, A.M. and Vogler, E.A. (2007) Influence of Substratum Surface Chemistry/Energy and Topography on the Human Fetal Osteoblastic Cell Line hFOB 1.19: Phenotypic and Genotypic Responses Observed in Vitro. Biomaterials, 28, 4535-4550. https://doi.org/10.1016/j.biomaterials.2007.06.016

[3] Zhou, R., Wei, D.Q., Cao, J.Y., Feng, W., Cheng, S., Du, Q., et al. (2015) Synergistic Effects of Surface Chemistry and Topologic Structure from Modified Microarc Oxidation Coatings on Ti Implants for Improving Osseointegration. ACS Applied Materials \& Interfaces, 7, 8932-8941. https://doi.org/10.1021/acsami.5b02226

[4] Anitua, E., Piñas, L., Murias, A., Prado, R. and Tejero, R. (2015) Effects of Calcium Ions on Titanium Surfaces for Bone Regeneration. Colloids and Surfaces B: Biointerfaces, 130, 173-181. https://doi.org/10.1016/j.colsurfb.2015.04.006

[5] Hanawa, T. (2019) Titanium-Tissue Interface Reaction and Its Control with Surface Treatment. Frontiers in Bioengineering and Biotechnology, 7, 170. https://doi.org/10.3389/fbioe.2019.00170

[6] Zhong, W.Y., Li, J.X., Hu, C.B., Quan, Z.X., Jiang, D.M., Huang, G.B. and Wang, Z.G. (2020) 3D-Printed Titanium Implant-Coated Polydopamine for Repairing Femoral Condyle Defects in Rabbits. Journal of Orthopaedic Surgery and Research, 15, Article No. 102. https://doi.org/10.1186/s13018-020-01593-x

[7] Kunzler, T.P., Drobek, T., Schuler, M. and Spencer, N.D. (2007) Systematic Study of Osteoblast and Fibroblast Response to Roughness by Means of Surface-Morphology Gradients. Biomaterials, 28, 2175-2182. https://doi.org/10.1016/j.biomaterials.2007.01.019

[8] Anselme, K., Bigerelle, M., Noël, B., Iost, A. and Hardouin, P. (2002) Effect of Grooved Titanium Substratum on Human Osteoblatic Cell Growth. Journal of 
Biomedical Materials Research, 60, 529-540. https://doi.org/10.1002/jbm.10101

[9] Boyan, B.D., Lohmann, C.H., Sisk, M., Liu, Y., Sylvia, V.L., Cochran, D.L., et al. (2001) Both Cyclooxygenase-1 and Cyclooxygenase-2 Mediate Osteoblast Response to Titanium Surface Roughness. Journal of Biomedical Materials Research, 55, 350-359.

https://doi.org/10.1002/1097-4636(20010605)55:3<350::AID-JBM1023>3.0.CO;2-M

[10] Khang, D., Lu, J., Yao, C., Haberstroh, K.M. and Webster, T.J. (2008) The Role of Nanometer and Sub-Micron Surface Features on Vascular and Bone Cell Adhesion on Titanium. Biomaterials, 29, 970-983.

https://doi.org/10.1016/j.biomaterials.2007.11.009

[11] Fiejdasz, S., Szczubiałka, K., Lewandowska-Łańcucka, J., Osyczka, A.M. and Nowakowska, M. (2013) Biopolymer-Based Hydrogels as Injectable Materials for Tissue Repair Scaffolds. Biomedical Materials, 8, Article ID: 035013. https://doi.org/10.1088/1748-6041/8/3/035013

[12] Ho, T., Ghochaghi, N. and Tepper, G. (2013) Development of Magnetic Fabrics with Tunable Hydrophobicity. Journal of Applied Polymer Science, 130, 2352-2358. https://doi.org/10.1002/app.39340

[13] Sato, M., Slamovich, E.B. and Webster, T.J. (2005) Enhanced Osteoblast Adhesion on Hydrothermally Treated Hydroxyapatite/Titania/Poly(Lactide-co-Glycolide) Sol-gel Titanium Coatings. Biomaterials, 26, 1349-1357. https://doi.org/10.1016/j.biomaterials.2004.04.044

[14] Ryu, J., Ku, S.H., Lee, H. and Park, C.B. (2010) Mussel-Inspired Polydopamine Coating as a Universal Route to Hydroxyapatite Crystallization. Advanced Functional Materials, 20, 2132-2139. https://doi.org/10.1002/adfm.200902347

[15] Lee, H., Dellatore, S.M., Miller, W.M. and Messersmith, P.B. (2008) Mussel-Inspired Surface Chemistry for Multifunctional Coatings. Science, 318, 426-430. https://doi.org/10.1126/science.1147241

[16] Zhe, W., Dong, C.F, Yang, S.F., Zhang, D.W., Xiao, K. and Li, X.G. (2016) Facile Incorporation of Hydroxyapatite onto an Anodized Ti Surface via a Mussel Inspired Polydopamine Coating. Applied Surface Science, 378, 496-503. https://doi.org/10.1016/j.apsusc.2016.03.094

[17] Hannink, G. and Arts, J.J.C. (2011) Bioresorbability, Porosity and Mechanical Strength of Bone Substitutes: What Is Optimal for Bone Regeneration? Injury, 42, S22-S25. https://doi.org/10.1016/j.injury.2011.06.008

[18] Cai, Y.L., Wang, X.Y., Poh, C.K., Tan, H.C., Soe, M.T., Zhang, S., et al. (2014) Accelerated Bone Growth in Vitro by the Conjugation of BMP2 Peptide with Hydroxyapatite on Titanium Alloy. Colloids and Surfaces B: Biointerfaces, 116, 681-686. https://doi.org/10.1016/j.colsurfb.2013.11.004

[19] Huang, S., Liang, N., Hu, Y., Zhou, X. and Abidi, N. (2016) Polydopamine-Assisted Surface Modification for Bone Biosubstitutes. BioMed Research International, 2016, Article ID: 2389895. https://doi.org/10.1155/2016/2389895

[20] Loiselle, A.E., Wei, L., Faryad, M., Paul, E.M., Lewis, G.S., Gao, J., et al. (2013) Specific Biomimetic Hydroxyapatite Nanotopographies Enhance Osteoblastic Differentiation and Bone Graft Osteointegration. Tissue Engineering Part A, 19, 1704-1712. https://doi.org/10.1089/ten.tea.2012.0560

[21] Zhou, P., Deng, Y., Lyu, B., Zhang, R.R., Zhang, H., Ma, H.W., et al. (2014) Rapidly-Deposited Polydopamine Coating via High Temperature and Vigorous Stirring: Formation, Characterization and Biofunctional Evaluation. PLOS ONE, 9, e113087. https://doi.org/10.1371/journal.pone.0113087 
[22] Tian, L.L., Prabhakaran, M.P., Ding, X., Kai, D. and Ramakrishna, S. (2012) Emulsion Electrospun Vascular Endothelial Growth Factor Encapsulated Poly (L-lactic acid-co- $\varepsilon$-caprolactone) Nanofibers for Sustained Release in Cardiac Tissue Engineering. Journal of Materials Science, 47, 3272-3281.

https://doi.org/10.1007/s10853-011-6166-4

[23] Yan, Y., Chibowski, E. and Szcześ, A. (2017) Surface Properties of Ti-6Al-4V Alloy Part I: Surface Roughness and Apparent Surface Free Energy. Materials Science and Engineering: C, 70, 207-215. https://doi.org/10.1016/j.msec.2016.08.080

[24] Lai, M., Cai, K.Y., Zhao, L., Chen, X.Y., Hou, Y.H. and Yang, Z.X. (2011) Surface Functionalization of $\mathrm{TiO}_{2}$ Nanotubes with Bone Morphogenetic Protein 2 and Its Synergistic Effect on the Differentiation of Mesenchymal Stem Cells. Biomacromolecules, 12, 1097-1105. https://doi.org/10.1021/bm1014365

[25] Dohan Ehrenfest, D.M., Coelho, P.G., Kang, B.S., Sul, Y.T. and Albrektsson, T. (2010) Classification of Osseointegrated Implant Surfaces: Materials, Chemistry and Topography. Trends in Biotechnology, 28, 198-206. https://doi.org/10.1016/j.tibtech.2009.12.003

[26] Lim, J.Y., Liu, X.M., Vogler, E.A. and Donahue, H.J. (2004) Systematic Variation in Osteoblast Adhesion and Phenotype with Substratum Surface Characteristics. Journal of Biomedical Materials Research Part A, 68A, 504-512. https://doi.org/10.1002/jbm.a.20087

[27] Lim, J.Y., Taylor, A.F., Li, Z., Vogler, E.A. and Donahue, H.J. (2005) Integrin Expression and Osteopontin Regulation in Human Fetal Osteoblastic Cells Mediated by Substratum Surface Characteristics. Tissue Engineering, 11, 19-29. https://doi.org/10.1089/ten.2005.11.19

[28] Zhou, F.Y., Qiu, K.J., Li, H.F., Huang, T., Wang, B.L., Li, L., et al. (2013) Screening on Binary Zr-1X (X= Ti, Nb, Mo, Cu, Au, Pd, Ag, Ru, Hf and Bi) Alloys with Good in Vitro Cytocompatibility and Magnetic Resonance Imaging Compatibility. Acta Biomaterialia, 9, 9578-9587. https://doi.org/10.1016/j.actbio.2013.07.035

[29] Kilian, K.A., Bugarija, B., Lahn, B.T. and Mrksich, M. (2010) Geometric Cues for Directing the Differentiation of Mesenchymal Stem Cells. Proceedings of the National Academy of Sciences of the United States of America, 107, 4872-4877. https://doi.org/10.1073/pnas.0903269107 